\title{
MELHORIA DO TRABALHO DOCENTE E DE GESTÃO NUMA ESCOLA PÚBLICA EM SANTA CATARINA POR MEIO DE PESQUISA DE SATISFAÇÃO DO CLIENTE
}

http://dx.doi.org/10.5902/2318133853179

\author{
Flávio Booz ${ }^{1}$ \\ Rozane Fermino² \\ Camila Grimes ${ }^{3}$
}

\begin{abstract}
Resumo
Na Escola de Educação Básica Manoel Vicente Gomes, da rede pública do Estado de Santa Catarina, foi implantada uma prática para avaliação da qualidade dos serviços, chamada de Feedback dos professores, cuja versão atual acontece por meio de um instrumento de geração de dados elaborado por gestores e validado pela comunidade escolar, constituindo uma prática que permitiu produzir uma visão coletiva de qualidade do serviço dos professores e gestores na visão dos estudantes e professores. Neste texto apresenta-se o processo de elaboração do documento e a implantação no ano de 2019 , discute-se os resultados da mesma e a forma de análise destes resultados pela gestão. Por fim, demonstra-se como uma pesquisa de qualidade dos serviços permitiu a organização escolar repensar sua prática docente e de gestão.

Palavras-chave: qualidade do serviço, práticas de gestão escolar, organização do trabalho pedagógico.
\end{abstract}

\section{IMPROVING TEACHING AND MANAGEMENT WORK IN A PUBLIC SCHOOL IN SANTA CATARINA, THROUGH A CUSTOMER SATISFACTION SURVEY}

\begin{abstract}
The Manoel Vicente Gomes School, from the public system in the state of Santa Catarina, implemented an evaluating practice of the services quality called Teachers Feedback. The current version of the Project is a data generation tool developed by managers and validated by the school community, as a practice that allowed the development of a collective view of teachers and managers services quality from students and teachers perspective. The research presents the process of data gathering and project implementation in 2019, also discusses the results found and its analysis by the management. In conclusion, this result shows how important a quality service survey is for the school organization to rethink management's practice.

Key-words: quality of services; school management practices; organization of pedagogical work.
\end{abstract}

\footnotetext{
${ }^{1}$ Escola de Educação Básica São João Batista, SED/SC, Brasil. E-mail: flaviobooz@gmail.com.

2 Escola de Educação Básica Manoel Vicente Gomes, SED/SC Brasil. E-mail: profrozanefermino@gmail.com.

3 Universidade Regional de Blumenau, Brasil. E-mail: cgrimes@furb.br.

\begin{tabular}{|l|l|l|l|l|l|}
\hline Regae: Rev. Gest. Aval. Educ. & Santa Maria & v. 10 & n. 19 & e53179, p. 1-14 & 2021
\end{tabular}
}




\section{Introdução}

egundo Parasuramanl, ZeithamllI e Berrylll (2006) "a literatura ainda não é 1 suficientemente rica para fornecer uma base conceitual sólida para a investigação da qualidade de serviços" e, no imaginário social acerca das variáveis para esta qualidade na educação, são comuns discursos sobre a presença de aspectos da família do estudante muitas vezes subestimando e até desconsiderando a qualidade do trabalho docente como determinante no resultado dos processos de ensinar e aprender, na constituição da vida escolar e, por tanto, na qualidade da educação (Felício; Fernandes, 2005).

As práticas de gestão escolar corroboram os referenciais de qualidade, uma vez que impactam diretamente nas práticas dos demais agentes e variáveis do processo. Destacamos a organização do trabalho pedagógico como eixo para as práticas em gestão que visem a qualificar ou mensurar a qualidade dos processos de ensinar e de aprender. Segundo Vasconcellos (2017) os eixos do trabalho pedagógico são o trabalho com o conhecimento, a organização da coletividade e o relacionamento interpessoal. Implica, por tanto, considerar não apenas o ofício de mestre, como também o ofício de estudante, pois, a aprendizagem, embora se dando num contexto social, depende, antes de tudo, da ação do aluno; além disto, o reconhecimento da atividade discente é decorrente de assumirmos uma linha de desenvolvimento de autonomia, de elaboração de projeto de vida. (Vasconcellos, 2019, p. 13)

Cabe então a gestão escolar, no contexto de organização do trabalho pedagógico, mapear a realidade das práticas docentes para então propor as mudanças necessárias para melhorar os processos de ensinar e aprender. Neste processo de levantar informações sobre o que está acontecendo nas práticas docentes da escola é comum que a gestão escolar use de conceitos como a avaliação institucional para propor caminhos e aferir significados aos dados que pretende coletar. Para tanto, entendemos que uma avaliação funcional requer convergência em todos os setores e que deve ser legitimada por aqueles a quem se aplica para ter sucesso.

Para Vasconcellos (2019) uma avaliação da qualidade da prática docente requer a transformação institucional, uma vez que esta avaliação precisa não apenas números do rendimento, mas também a discussão da visão coletiva da distância entre o desejo, a qualidade almejada e a prática. Neste contexto de buscou-se analisar como uma pesquisa de qualidade do serviço, na visão de professores e estudantes, pode aferir indicadores substanciais para a elaboração de um referencial coletivo de qualidade numa escola da rede pública estadual de Santa Catarina.

\section{Processos metodológicos}

As informações do processo foram coletadas a partir dos instrumentos de geração de dados utilizados pela gestão escolar e dos relatos dos professores e estudantes presentes num diário reflexivo em que se registrou as impressões dos professores avaliados. Relatamos um estudo referente as avaliações dos servidores da Escola de Educação Básica Manoel Vicente Gomes, da rede pública do estado de Santa Catarina, onde a escolha da métrica por Customer Satisfaction Score - CSAT - permitiu o 
levantamento de informações consistentes sobre a prática docente e, portanto, sobre a rotina da instituição como um todo na visão dos estudantes. Por fim, apresentamos os resultados que a escola obteve a partir deste novo processo de avaliação dos docentes e as decisões do coletivo de professores e gestores a cerca destas informações.

A iniciativa da avaliação partiu dos gestores da unidade escolar desde 2016. A partir do seu percurso formativo, de suas experiências práticas e embasamentos teóricos, considerando ainda o projeto político-pedagógico da escola, foi elaborado o instrumento de geração de dados, bem como realizou-se a validação o mesmo pela comunidade escolar.

\section{O processo de feedback dos professores}

De 2016 até início de 2019, como atividade paralela e complementar ao conselho de classe, a gestão da E. E. B. Manoel Vicente Gomes, organizava bimestralmente um momento de feedback com os servidores. Os gestores reuniam-se com as turmas de estudantes e ouviam suas manifestações. Durante a conversa os gestores faziam anotações que julgavam importantes. A partir daí foi elaborado um instrumento chamado de Feedback dos professores. Nos dias que sucediam os conselhos de classe realizavase uma reunião para orientar cada professor individualmente. A referência de qualidade acontecia pela observação dos feedbacks anteriores e não havia um norteador geral, assim sendo, aspectos dignos de registro na avaliação de um servidor eram desconsiderados na de outro.

Além da subjetividade percebeu-se que o processo não era capaz de formalizar qualitativamente ou quantitativamente a transformação da prática docente e compreender a dinâmica da escola. Essa fragilidade do processo também era sentida pelos professores, como podemos ver na proposição do professor-01:

Não proporcionava uma reflexão sobre minha prática docente, pois eram apenas tópicos pontuais, não aprofundados, então, apesar de haver uma avaliação, esta não me dava uma direção do que eu deveria melhorar e o quanto era preciso repensar minhas atitudes e metodologias. (Professor01, diário reflexivo 2019/2)

A partir destas fragilidades foi proposto, em 2019, um novo modelo baseado em indicadores para melhorias efetivas na rotina escolar (Brandalise, 2010). O novo processo baseou-se na métrica CSAT e levou em conta a busca de qualidade por ações da rotina docente. A partir de então os estudantes passaram a atribuir valores de qualidade da prática docente de forma mais objetiva.

Percebendo que a prática dos gestores e dos professores divergia em muitos fazeres, foram elaboradas duas listas distintas: uma para o professor e outra para o gestor. Os itens elencados para o professor foram: avaliação; postura profissional; planejamento e organização; domínio de conteúdo; domínio de classe; comunicação; assiduidade e pontualidade. Já os itens elencados para o gestor foram assiduidade e pontualidade; gestão da rotina escolar; gestão de pessoas; gestão acadêmica; postura profissional e respeito. 
Nesse ponto era necessário validar o documento e o perfil de excelência profissional que este propunha, tanto entre estudantes que avaliariam, quanto entre professores que seriam avaliados, visto que ambos ainda não conheciam o novo formato. Foram distribuídas cópias do instrumento para revisão dos descritores e o envio de colaborações.

Considerando as anotações deste coletivo os gestores substituíram os valores numéricos por conceitos - deixou a desejar, regular, bom, ótimo e excelente - e também os conceitos passaram a ser representados por ícones conforme podemos observar nos instrumentos de geração de dados para distanciar mais a métrica da pesquisa de satisfação com a da avaliação dos estudantes nas disciplinas. Também foram melhorados os eixos e respectivos descritores, resultando nos seguintes itens a avaliar.

Para professores:

- Assiduidade e pontualidade: é assíduo; apresenta-se para o trabalho no horário; mantém-se em seu posto de trabalho nos horários pré-estabelecidos durante todo o período de trabalho.

- Avaliação: as avaliações permitem que o aluno demonstre o que aprendeu; corrige, entrega e publica as notas no professor on-line no prazo máximo de 15 dias; realiza as avaliações com perguntas objetivas/subjetivas trimestralmente; sempre que necessário retoma os conteúdos; oferece recuperações paralelas; as avaliações são compatíveis com os conteúdos estudados.

- Comunicação: os materiais impressos utilizados são de qualidade; tem clareza na exposição dos conteúdos; domina a norma culta da língua portuguesa; utiliza o quadro branco e de giz de forma organizada e legível.

- Domínio de classe: lidera a turma com respeito e autoridade; mantém a disciplina durante a aula; tem controle e atenção aos alunos que deixam a sala.

- Domínio de conteúdo: demonstra segurança em relação aos conteúdos da aula; consegue esclarecer dúvidas dos alunos sobre os conteúdos.

- Incentivo à pesquisa: as atividades de pesquisa despertam a curiosidade nos estudantes; as temáticas de pesquisa são do interesse dos alunos; oferece fontes de pesquisa para as atividades propostas.

- Planejamento e organização: permanece na sala durante toda a aula; o material didático do professor é organizado; tem uma forma organizada de armazenar as atividades que recolhe dos estudantes; os alunos estão sempre ocupados com atividades durante as aulas; utiliza vídeos e filmes, com real valor para a aprendizagem e observando a censura etária; traz o material impresso na quantidade exata para a toda a turma evitando saídas desnecessárias; consegue adiantar informações sobre as próximas aulas e conteúdo; utiliza caderno próprio com registro da aula planejada.

- Postura profissional e respeito ao aluno: é zeloso com os materiais e patrimônio da escola; na falta justificada do estudante, informa em tempo hábil prazos e formas de retomada das atividades; demonstra cordialidade e respeito aos outros professores e funcionários; intervêm em situações de indisciplina minimizando os conflitos; responde questionamentos dos estudantes com respeito; utiliza o celular apenas para as atividades da aula; é exemplo no cumprimento das regras cobradas dos alunos; respeita e pratica o horário de leitura. 
- Registro de ocorrências: registra frequentemente no diário casos de uso do celular; registra frequentemente no diário quando o aluno não tem material para o momento da leitura; registra frequentemente no diário quando o estudante não faz em casa ou na escola as atividades, provas, trabalhos e recuperações; quando faz registros no diário coleta assinatura dos estudantes envolvidos; encaminha situações de indisciplina ou violência para a direção ou ao Núcleo de Educação e Prevenção (NEPRE).

- Uso de recursos: comumente utiliza vídeos, filmes, slides ou outro material digital nas atividades; comumente utiliza textos da atualidade; comumente utiliza imagens, mapas, cartazes e textos de diferentes gêneros nas atividades; comumente utiliza o livro didático nas atividades; comumente utiliza o quadro branco e quadro de giz; utiliza nas aulas outros espaços do ambiente escolar além da sala regular: biblioteca, laboratório, cozinha, etc.

Para os gestores:

- Assiduidade e pontualidade: é assíduo; apresenta-se para o trabalho com antecedência; mantém-se em seu posto de trabalho nos horários pré-estabelecidos durante todo o período de trabalho.

- Comunicação: demonstra segurança em relação às orientações prestadas aos servidores; faz comunicação de mudanças no funcionamento geral da escola em tempo hábil para os servidores e estudantes; está disponível para ouvir os servidores e estudantes; domina e utiliza a norma culta da língua portuguesa para assuntos profissionais; promove a troca de informações entre os docentes sobre o andamento do ano letivo e aprendizagem dos estudantes; é respeitoso com servidores, estudantes e pais; dificilmente interrompe as aulas; da os recados na sala aula com brevidade.

- Gestão da rotina escolar: exerce liderança e tem voz de comando; apoia e faz cumprir as rotinas de controle de disciplina dos estudantes; fornece apoio aos projetos e atividades extraclasse dos docentes; garante que os sinais de troca de aula sejam pontuais; encaminha alunos para a sala no início do período e após o recreio; registra as ocorrências com alunos comunicadas pelos servidores e toma providências; faz registros e tem conhecimento do andamento dos casos de apoia; faz registros e tem conhecimento do andamento dos casos de Nepre.

- Gestão de pessoas: demonstra conhecer o estatuto do magistério e a lei do ACT; mantém organizados os documentos entregues pelos servidores; faz as anotações de faltas e trocas de períodos no livro ponto em tempo hábil; incentiva os servidores ao aperfeiçoamento e a participar de formações continuadas; trata todos os servidores com equidade; age de forma preventiva nos desafios gerenciais da sua função e da escola; age de forma proativa minimizando conflitos entre servidores, estudantes e pais; age de forma proativa minimizando os problemas da escola; faz críticas particulares em particular; permite e incentiva os servidores a participar das decisões da escola.

- Gestão acadêmica: sana de imediato dúvidas sobre a avaliação na perspectiva da rede estadual e do PPP; garante que todo o estudante frequentando esteja matriculado na turma; mantém organizados os documentos do registro escolar - atas, diários, boletins e históricos - e consegue recuperá-los do arquivo a qualquer tempo; demonstra conhecer a

\footnotetext{
${ }^{4}$ Programa de enfrentamento de violências e vulnerabilidades da rede estadual de Santa Catarina.

Regae: Rev. Gest. Aval. Educ. $\quad$ Santa Maria v. 10 n. 19 e53179, p. 1-14 
BNCC e a PC/SC; tem conhecimento do andamento da avaliação nas disciplinas; propõe soluções ou alternativas para as dificuldades de sala de aula; acompanha o trabalho do professor.

- Postura profissional e respeito: é zeloso com os materiais e patrimônio da escola; demonstra cordialidade e respeito aos professores, estudantes e funcionários; utiliza o celular apenas para as atividades de sua competência; é exemplo no cumprimento das regras cobradas dos alunos; respeita e participa dos projetos da escola, valorizando 0 trabalho dos alunos e professores; em caso de necessidade presta serviços de outra natureza além da sua função.

No primeiro mês do segundo semestre letivo os gestores levaram os instrumentos de geração de dados para os que os estudantes fizessem a avaliação. Também nesta época os professores fizeram a avaliação dos gestores. O momento de discussão coletiva foi o conselho de classe do $2 \stackrel{0}{ }$ trimestre, quando foram apresentados os resultados.

\section{Os resultados do novo feedback dos professores}

Tendo como referência a busca por excelência na visão dos avaliadores, foi escolhida, como visão de base para qualidade, o índice de 60\% de marcações da opção excelente. Esse referencial foi utilizado, tanto na análise dos eixos, quanto dos descritores. Na média geral dos gestores não houve eixo com referencial abaixo de $60 \%$, como pode-se ver na figura 1.

Figura 1 -

Média geral da avaliação dos gestores realizada pelos professores.

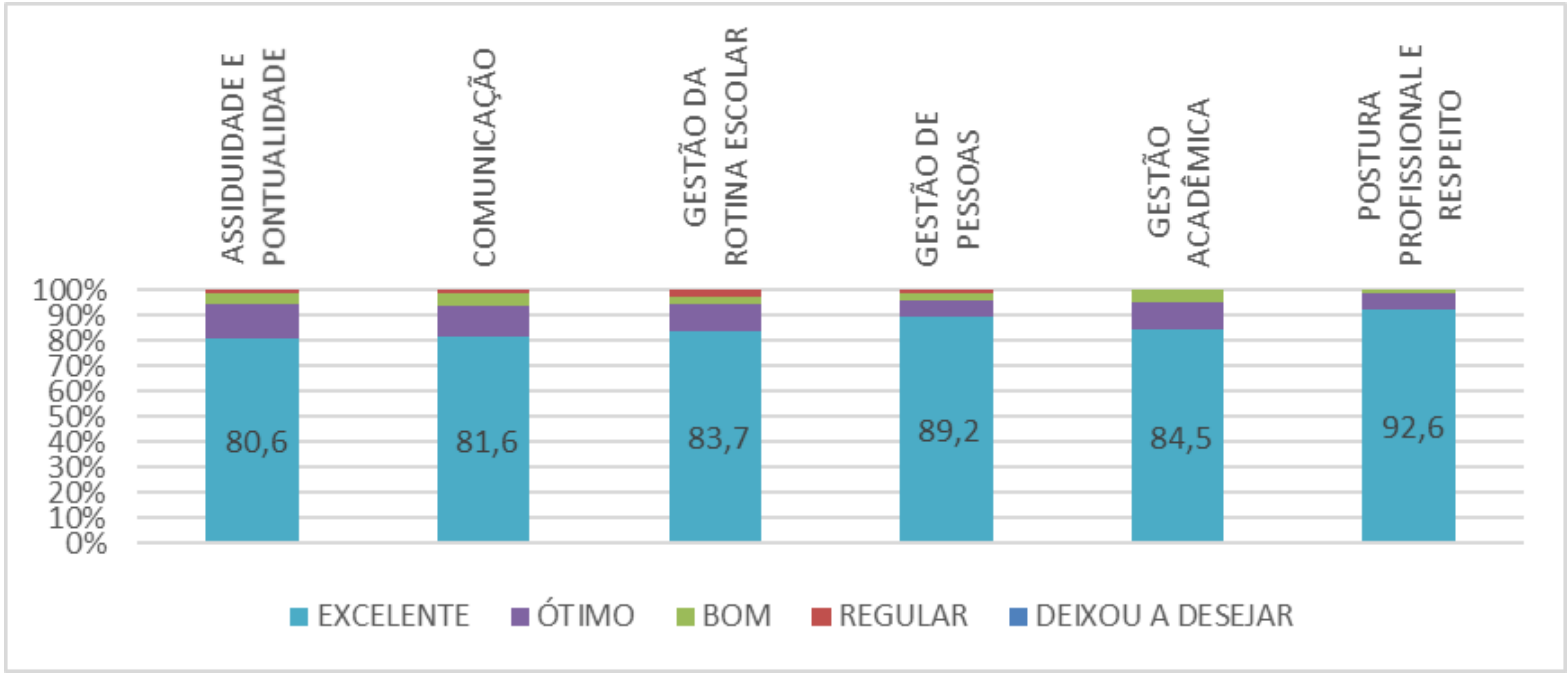

Fonte: autores.

Analisando a média geral dos professores, figura 2, houve apenas um eixo com referencial abaixo da média seis, o de incentivo à pesquisa, com $58 \%$ de excelência foi 0 pior avaliado. Também se destaca o eixo do uso de recursos que, mesmo atingindo $61 \%$ de excelência, foi considerado um item a ser discutido visto a proximidade ao $60 \%$. 
Figura 2 -

Média geral da avaliação dos professores realizada pelos estudantes.

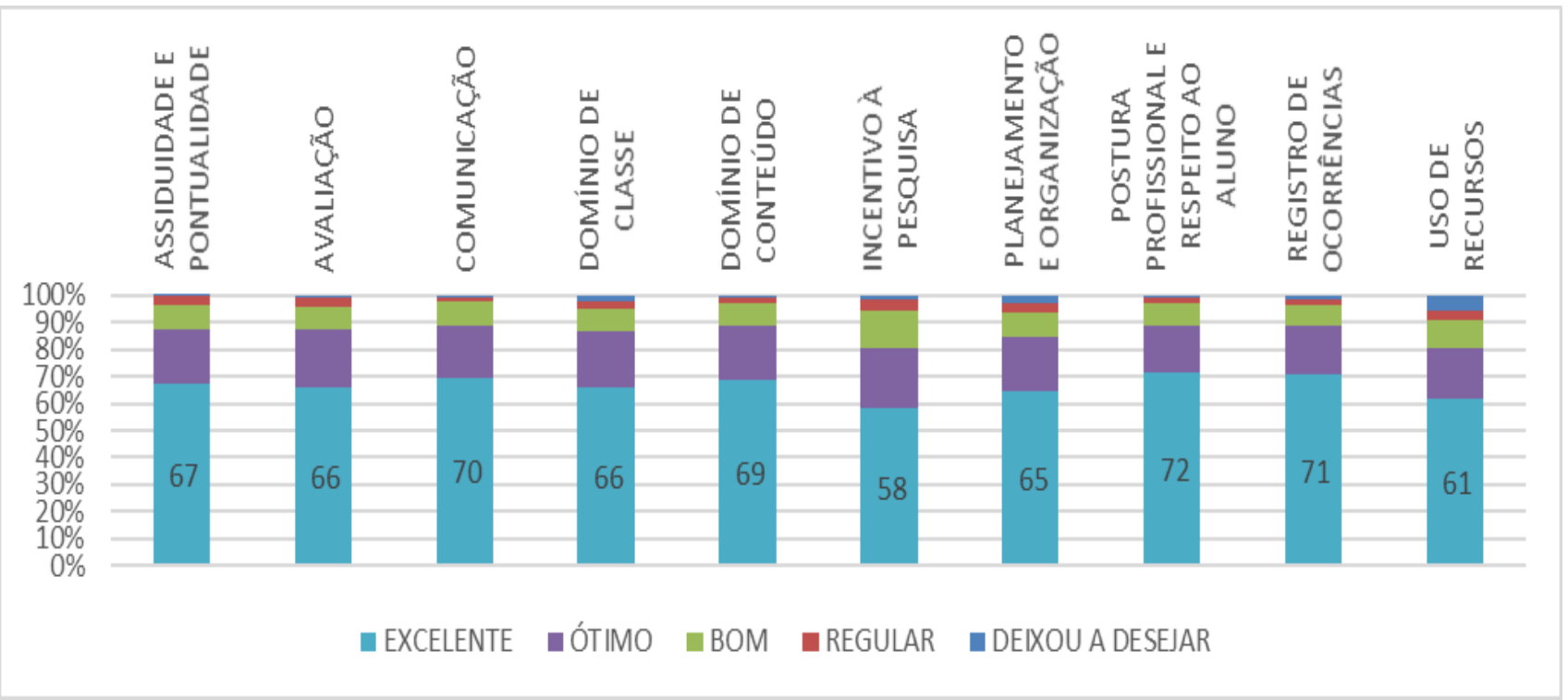

Fonte: autores.

Percebe-se uma diferença aproximada de $15 \%$ entre os índices mensurados e os índices idealizados (100\%). Esta análise aponta para a necessidade de os gestores refletirem as práticas, pensando em atividades dos eixos com menor índice de excelência, como 'apresentar-se para o trabalho com antecedência', descritor de menor resultado de excelência $(72,2 \%)$ do eixo assiduidade e pontualidade, com menor resultado quantitativo de excelência (80\%).

Mesmo com indicadores razoavelmente positivos, podemos entender o percentual total $(100 \%)$ de excelência como ideal, uma vez que, quantitativamente, apenas este demonstra a satisfação do cliente sem ressalvas de qualquer ordem. O professor-02 corrobora esta perspectiva: "Se o objetivo é o ofertar o serviço com qualidade não podemos nos contentar com nada menos que o reconhecimento de excelência por parte dos nossos professores" (professor-02, diário reflexivo 2019/2).

Observamos também que ao considerar a média geral por descritor e não apenas por eixo, vamos encontrar sobre os gestores, no descritor 'Dificilmente interrompe as aulas' o percentual geral de $47,2 \%$, menor de todos os avaliados. Fazendo a mesma leitura nos dados da média geral por descritor, agora com os professores, encontramos 0 menor índice de excelência (53\%) no descritor 'Utiliza vídeos e filmes, com real valor para a aprendizagem e observando a censura etária', que está no eixo do 'Planejamento e organização', que na análise por eixo tem $65 \%$ de excelência. Os índices divergentes entre eixos e descritores advertem sobre a necessidade de uma reflexão mais detalhada dos dados obtidos, e das particularidades da prática de cada servidor mensuradas nos descritores.

Dentre as manifestações dos servidores a respeito do processo, destacam-se o professor-01, que ressalta como a avaliação pode nortear sua atuação docente no que tange a melhorar sua prática em sala de aula: 
O sistema de avaliação institucional aplicado atualmente é algo sensacional. Muito específico e relevante. Através dessa avaliação consegui ter acesso a informações que não teria de nenhuma outra forma, posso reavaliar minha prática e enxergar através dos olhos dos estudantes. (professor-01, diário reflexivo 2019/2)

O processo de geração de dados sobre as práticas docentes e de gestão, elaborado e aplicado na E. E. B. Manoel Vicente Gomes, se constituem como um instrumento de reflexão referente à qualidade de desenvolvimento do projeto político-pedagógico da escola, sendo referencial para o planejamento estratégico da escola.

\section{Considerações finais}

"A qualidade é um construto vago e indistinto. Muitas vezes confundida com adjetivos imprecisos, como bondade, luxo, brilho ou peso" (Crosby, 1979 apud Parasuraman; Zeithaml; Berry, 2006) e, por isso, buscar formas de referenciar boas práticas na execução de serviços na educação pública é assumir o papel da escola na vida do cidadão e da oferta de educação de qualidade.

O processo de elaboração dos instrumentos de coleta de dados ilustra uma visão coletiva de qualidade do trabalho docente, na medida em que eixos e descritores foram elaborados em regime colaborativo e reestruturados a partir destas colaborações. Os dados do instrumento de coleta dos dados e os quantitativos atribuídos pelos entrevistados resultaram numa visão de como são os servidores da E. E. B. Manoel Vicente Gomes.

Ainda que a comunidade escolar tenha reconhecido a pesquisa de satisfação como funcional, é possível aprimorar os descritores numa perspectiva de garantir que todos compreendam de fato a visão de professor e gestor a que se refere e os métodos de aplicação numa perspectiva de busca por dinâmicas mais rápidas e eficazes para tabular resultados. Neste sentido, a utilização de uma pesquisa de qualidade, com a utilização da métrica de pontuação de satisfação do cliente, permitiu a comunidade escolar reconhecer aspectos mais minuciosos da prática docente materializando a diferença entre o desejo e o real, entre o que que é oferecido e o que deve ser feito, enfim uma demanda mensurável de qualidade.

\section{Referências}

BOGDAN, Robert; BIKLEN, Sari Knopp. Investigação qualitativa em educação: uma introdução à teoria e aos métodos. Porto: Porto, 1994.

BRANDALISE, Mary Ângela Teixeira. Avaliação institucional da escola: conceitos, contextos e práticas. Olhar de Professor, Ponto Grossa, v. 13, n. 2, 2010, p. 315-330.

COELHO, Allexandro Mori; CORSEUIL, Carlos Henrique. Diferenciais salariais no Brasil: um breve panorama. In: CORSEUIL, Carlos Henrique (ed.). Estrutura salarial: aspectos conceituais e novos resultados para o Brasil. Rio de Janeiro: Ipea, 2002, p. 67-100.

COLAÇO, Silvania Faccin. A travessia do ser aluno para o ser professor: práticas de letramento pedagógico no Pibid. Pelotas: UFPel, 2015. 212f. tese (doutorado em Letras). Programa de Pós-Graduação em Letras, Universidade Católica de Pelotas. 
CROSBY, Philip Bayard. Quality is free: the art of making quality certain. Nova lorque: New American Library, 1979.

DEMO, Pedro. Ironias da educação. Rio de Janeiro: DP\&A, 2000.

FELÍCIO, Fabiana de; FERNANDES, Reynaldo. O efeito da qualidade da escola sobre o desempenho escolar: uma avaliação do ensino fundamental no Estado de São Paulo. ENCONTRO NACIONAL DE ECONOMIA, 33, 2005. Anais ... Natal: Anpec, 2005. Disponível em http://www.anpec.org.br/encontro2005/artigos/A05A157.pdf. Acesso em 8 jan. 2020.

FRITZEN, Maristela Pereira. O olhar da etnografia no fazer pesquisa qualitativa: algumas reflexões teórico-metodológicas. In: FRITZEN, Maristela Pereira; LUCENA, Maria Inêz Probst (orgs.) O olhar da etnografia em contextos educacionais: interpretando práticas de linguagem. Blumenau: Furb, 2012, p. 55-71.

MAJOR GERCINO. Projeto político-pedagógico da Escola de Educação Básica Manoel Vicente Gomes. Florianópolis: SED/SC, 2019.

PARASURAMAN, Parsu; ZEITHAML, Valarie A; BERRY, Leonard L. Um modelo conceitual de qualidade de serviço e suas implicações para a pesquisa no futuro. $R A E-$ Revista de Administração de Empresas, v. 46, n. 4, 2006, p. 96-108.

VASCONCELLOS, Celso dos Santos. Coordenação do trabalho pedagógico. São Paulo: Cortez. 2019

Flávio Booz é assistente de educação na Escola de Educação Básica São João Batista, SED/SC.

Orcid: https://orcid.org/0000-0002-3518-4474.

Endereço: Rua José Antônio Soares, 2501 - 88240-000 - São João Batista - SC Brasil.

E-mail: flaviobooz@gmail.com.

Rozane Fermino é professora na Escola de Educação Básica Manoel Vicente Gomes, SED/SC.

Orcid: https://orcid.org/0000-0002-5281-4773.

Endereço: Rua Geral Pulgas, s/n - 88240-000 - Distrito de Tigipió - São João Batista - SC - Brasil.

E-mail: rozanefermino2018@gmail.com.

Camila Grimes é estudante do curso de doutorado em Educação na Universidade Regional de Blumenau.

Orcid: https://orcid.org/0000-0003-0105-4046.

Endereço: Rua Guilhermino Albanás, 743 - 88260-000 - Major Gercino - SC - Brasil. E-mail: cgrimes@furb.br. 
Ficha de avaliação de professores

Avaliação institucional dos professores $2^{\circ}$ trimestre

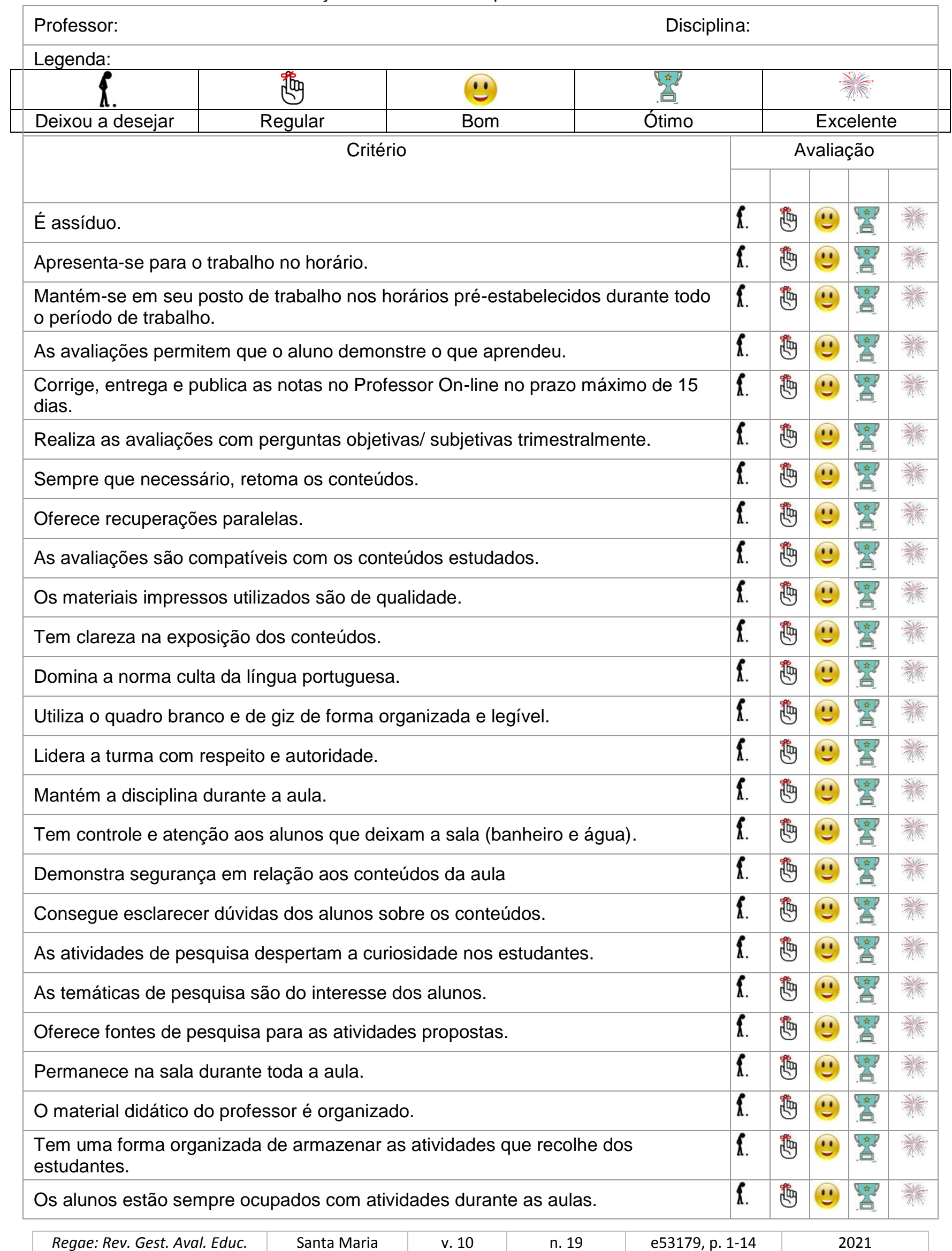




\begin{tabular}{|c|c|c|c|c|c|}
\hline $\begin{array}{l}\text { Utiliza vídeos e filmes, com real valor para a aprendizagem e observando a } \\
\text { censura etária. }\end{array}$ & f. & 曷 & (:) & 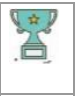 & 㭗: \\
\hline $\begin{array}{l}\text { Traz o material impresso na quantidade exata para a toda a turma evitando saídas } \\
\text { desnecessárias. }\end{array}$ & $\mathfrak{f}$ & 迎跑 & (1) & 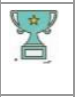 & 拳: \\
\hline Consegue adiantar informações sobre as próximas aulas e conteúdos. & f. & 䖧 & (1) & 高 & 橉 \\
\hline Utiliza caderno próprio com registro da aula planejada. & i. & 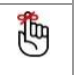 & (1) & 渵 & 橉 \\
\hline É zeloso com os materiais e patrimônio da escola. & i. & 笼 & (1) & $\begin{array}{l}\text { मक } \\
\text {. }\end{array}$ & 类: \\
\hline $\begin{array}{l}\text { Na falta justificada do estudante, informa em tempo hábil prazos e formas de } \\
\text { retomada das atividades. }\end{array}$ & f. & 第 & (1) & 㖣 & 㭗 \\
\hline Demonstra cordialidade e respeito aos outros professores e funcionários. & $\AA$ & 递 & (1) & 焉 & 楼 \\
\hline Intervêm em situações de indisciplina minimizando os conflitos. & f. & 遇 & (1) & 部 & 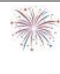 \\
\hline Responde questionamentos dos estudantes com respeito. & i. & 递 & (1) & . & 畨: \\
\hline Utiliza o celular apenas para as atividades da aula. & f. & 遇 & (:) & 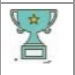 & 畨: \\
\hline É exemplo no cumprimento das regras cobradas dos alunos. & f. & 递 & (1) & 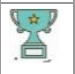 & 类 \\
\hline Respeita e pratica o horário de leitura. & i. & 遇 & (1) & 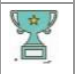 & 煞: \\
\hline Registra frequentemente no diário, casos de uso do celular. & f. & 题酸 & (1) & 落 & 解: \\
\hline $\begin{array}{l}\text { Registra frequentemente no diário, quando o aluno não tem material para o } \\
\text { momento da leitura. }\end{array}$ & i. & 题 & (1) & . & 粪: \\
\hline $\begin{array}{l}\text { Registra frequentemente no diário quando o estudante não faz em casa ou na } \\
\text { escola as atividades, provas, trabalhos e recuperações. }\end{array}$ & f. & 题 & (1) & . & 橉. \\
\hline Quando faz registros no diário, coleta assinatura dos estudantes envolvidos. & f. & 题 & (1) & 政 & 㭗 \\
\hline Encaminha situações de indisciplina ou violência para a direção ou Nepre. & f. & 迎 & (1) & 语 & 邹: \\
\hline Comumente utiliza vídeos, filmes, slides ou outro material digital nas atividades. & f. & 题 & (1) & $\begin{array}{l}\text { 部 } \\
\text {.0 }\end{array}$ & 秚: \\
\hline Comumente utiliza textos da atualidade. & f. & 题 & (1) & 离 & 触 \\
\hline $\begin{array}{l}\text { Comumente utiliza imagens, mapas, cartazes e textos de diferentes gêneros nas } \\
\text { atividades. }\end{array}$ & i. & 曷 & $(\because)$ & 政 & 㭗: \\
\hline Comumente utiliza o livro didático nas atividades. & $\AA$ & 题 & (1) & 离 & 楼 \\
\hline Comumente utiliza o quadro branco e quadro de giz. & f. & 跒 & $(1)$ & . & 磷 \\
\hline $\begin{array}{l}\text { Utiliza nas aulas outros espaços do ambiente escolar além da sala regular: } \\
\text { biblioteca, laboratório, cozinha, etc. }\end{array}$ & $\mathbb{f}$. & 遇 & (1) & . & 解 \\
\hline
\end{tabular}


Ficha de avaliação de gestores

Avaliação institucional - equipe gestora

Avaliado:

Período:

Professor avaliador:

Legenda:

\begin{tabular}{|c|c|c|c|c|}
\hline 8 & 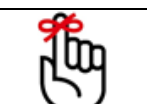 & 0 & $\begin{array}{l}80 \\
.85 \\
.50\end{array}$ & : \\
\hline Deixou a desejar & Regular & Bom & Ótimo & Excelente \\
\hline
\end{tabular}

Critério

Assiduidade e pontualidade

É assíduo.

Apresenta-se para o trabalho com antecedência.

Mantém-se em seu posto de trabalho nos horários préestabelecidos durante todo o período de trabalho.

Comunicação

Demonstra segurança em relação às orientações prestadas aos servidores.

Faz comunicação de mudanças no funcionamento geral da escola em tempo hábil para os servidores e estudantes.

Está disponível para ouvir os servidores e estudantes.

Domina e utiliza a norma culta da língua portuguesa para assuntos profissionais.

Promove a troca de informações entre os docentes sobre 0 andamento do ano letivo e aprendizagem dos estudantes.

É respeitoso com servidores, estudantes e pais.

Dificilmente interrompe as aulas.

Da os recados na sala aula com brevidade.

Gestão da rotina escolar

Exerce liderança e tem voz de comando.

Apoia e faz cumprir as rotinas de controle de disciplina dos estudantes.

Fornece apoio aos projetos e atividades extraclasse dos docentes.

Garante que os sinais de troca de aula sejam pontuais.

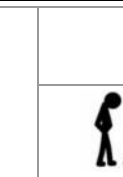

Avaliação

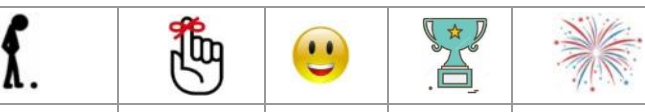
desejar

Deixou a Regular Bom Ótimo Excelente desejar

Deixou a Regular Bom Ótimo Excelente desejar

Deixou a Regular Bom Ótimo Excelente desejar

Deixou a Regular Bom Ótimo Excelente desejar

Deixou a Regular Bom Ótimo Excelente desejar

Deixou a Regular Bom Ótimo Excelente desejar

Deixou a Regular Bom Ótimo Excelente desejar

Deixou a Regular Bom Ótimo Excelente desejar

Deixou a Regular Bom Ótimo Excelente desejar

Deixou a Regular Bom Ótimo Excelente desejar

Deixou a Regular Bom Ótimo Excelente desejar 


\begin{tabular}{|c|c|c|c|c|c|}
\hline $\begin{array}{l}\text { Encaminha alunos para a sala no início do período e após } \\
\text { o recreio. }\end{array}$ & $\begin{array}{c}\text { Deixou a } \\
\text { desejar }\end{array}$ & Regular & Bom & Ótimo & Excelente \\
\hline $\begin{array}{l}\text { Registra as ocorrências com alunos comunicadas pelos } \\
\text { servidores e toma providências. }\end{array}$ & $\begin{array}{c}\text { Deixou a } \\
\text { desejar }\end{array}$ & Regular & Bom & Ótimo & Excelente \\
\hline $\begin{array}{l}\text { Faz registros e tem conhecimento do andamento dos casos } \\
\text { de APOIA }\end{array}$ & $\begin{array}{l}\text { Deixou a } \\
\text { desejar }\end{array}$ & Regular & Bom & Ótimo & Excelente \\
\hline $\begin{array}{l}\text { Faz registros e tem conhecimento do andamento dos casos } \\
\text { de NEPRE. }\end{array}$ & $\begin{array}{l}\text { Deixou a } \\
\text { desejar }\end{array}$ & Regular & Bom & Ótimo & Excelente \\
\hline \multicolumn{6}{|l|}{ Gestão de pessoas } \\
\hline $\begin{array}{l}\text { Demonstra conhecer o estatuto do magistério e a lei do } \\
\text { ACT. }\end{array}$ & $\begin{array}{l}\text { Deixou a } \\
\text { desejar }\end{array}$ & Regular & Bom & Ótimo & Excelente \\
\hline $\begin{array}{l}\text { Mantém organizados os documentos entregues pelos } \\
\text { servidores. }\end{array}$ & $\begin{array}{c}\text { Deixou a } \\
\text { desejar }\end{array}$ & Regular & Bom & Ótimo & Excelente \\
\hline $\begin{array}{l}\text { Faz as anotações de faltas e trocas de períodos no livro } \\
\text { ponto em tempo hábil. }\end{array}$ & $\begin{array}{l}\text { Deixou a } \\
\text { desejar }\end{array}$ & Regular & Bom & Ótimo & Excelente \\
\hline $\begin{array}{l}\text { Incentiva os servidores ao aperfeiçoamento e a participar } \\
\text { de formações continuadas. }\end{array}$ & $\begin{array}{l}\text { Deixou a } \\
\text { desejar }\end{array}$ & Regular & Bom & Ótimo & Excelente \\
\hline Trata todos os servidores com equidade. & $\begin{array}{l}\text { Deixou a } \\
\text { desejar }\end{array}$ & Regular & Bom & Ótimo & Excelente \\
\hline $\begin{array}{l}\text { Age de forma preventiva nos desafios gerenciais da sua } \\
\text { função e da escola. }\end{array}$ & $\begin{array}{l}\text { Deixou a } \\
\text { desejar }\end{array}$ & Regular & Bom & Ótimo & Excelente \\
\hline $\begin{array}{l}\text { Age de forma proativa minimizando conflitos entre } \\
\text { servidores, estudantes e pais. }\end{array}$ & $\begin{array}{l}\text { Deixou a } \\
\text { desejar }\end{array}$ & Regular & Bom & Ótimo & Excelente \\
\hline $\begin{array}{l}\text { Age de forma proativa minimizando os problemas da } \\
\text { escola. }\end{array}$ & $\begin{array}{l}\text { Deixou a } \\
\text { desejar }\end{array}$ & Regular & Bom & Ótimo & Excelente \\
\hline Faz críticas particulares em particular. & $\begin{array}{l}\text { Deixou a } \\
\text { desejar }\end{array}$ & Regular & Bom & Ótimo & Excelente \\
\hline $\begin{array}{l}\text { Permite e incentiva os servidores a participar das decisões } \\
\text { da escola. }\end{array}$ & $\begin{array}{l}\text { Deixou a } \\
\text { desejar }\end{array}$ & Regular & Bom & Ótimo & Excelente \\
\hline \multicolumn{6}{|l|}{ Gestão acadêmica } \\
\hline $\begin{array}{l}\text { Sana de imediato, dúvidas sobre a avaliação na } \\
\text { perspectiva da rede estadual e do PPP. }\end{array}$ & $\begin{array}{c}\text { Deixou a } \\
\text { desejar }\end{array}$ & Regular & Bom & Ótimo & Excelente \\
\hline $\begin{array}{l}\text { Garante que todo o estudante frequentando esteja } \\
\text { matriculado na turma. }\end{array}$ & $\begin{array}{l}\text { Deixou a } \\
\text { desejar }\end{array}$ & Regular & Bom & Ótimo & Excelente \\
\hline $\begin{array}{l}\text { Mantém organizados os documentos do registro escolar } \\
\text { (atas, diários, boletins e históricos) e consegue recuperá- } \\
\text { los do arquivo a qualquer tempo. }\end{array}$ & $\begin{array}{l}\text { Deixou a } \\
\text { desejar }\end{array}$ & Regular & Bom & Ótimo & Excelente \\
\hline Demonstra conhecer a BNCC e a PC/SC. & $\begin{array}{l}\text { Deixou a } \\
\text { desejar }\end{array}$ & Regular & Bom & Ótimo & Excelente \\
\hline $\begin{array}{l}\text { Tem conhecimento do andamento da avaliação nas } \\
\text { disciplinas. }\end{array}$ & $\begin{array}{l}\text { Deixou a } \\
\text { desejar }\end{array}$ & Regular & Bom & Ótimo & Excelente \\
\hline $\begin{array}{l}\text { Propõe soluções e/ou alternativas para as dificuldades de } \\
\text { sala de aula. }\end{array}$ & $\begin{array}{c}\text { Deixou a } \\
\text { desejar }\end{array}$ & Regular & Bom & Ótimo & Excelente \\
\hline Acompanha o trabalho do professor. & $\begin{array}{c}\text { Deixou a } \\
\text { desejar }\end{array}$ & Regular & Bom & Ótimo & Excelente \\
\hline \multicolumn{6}{|l|}{ Postura profissional e respeito } \\
\hline É zeloso com os materiais e patrimônio da escola. & $\begin{array}{l}\text { Deixou a } \\
\text { desejar }\end{array}$ & Regular & Bom & Ótimo & Excelente \\
\hline
\end{tabular}




\begin{tabular}{|l|c|l|l|l|l|}
\hline $\begin{array}{l}\text { Demonstra cordialidade e respeito aos professores, } \\
\text { estudantes e funcionários. }\end{array}$ & $\begin{array}{l}\text { Deixou a } \\
\text { desejar }\end{array}$ & Regular & Bom & Ótimo & Excelente \\
\hline $\begin{array}{l}\text { Utiliza o celular apenas para as atividades de sua } \\
\text { competência. }\end{array}$ & $\begin{array}{c}\text { Deixou a } \\
\text { desejar }\end{array}$ & Regular & Bom & Ótimo & Excelente \\
\hline $\begin{array}{l}\text { É exemplo no cumprimento das regras cobradas dos } \\
\text { alunos. }\end{array}$ & $\begin{array}{l}\text { Deixou a } \\
\text { desejar }\end{array}$ & Regular & Bom & Ótimo & Excelente \\
\hline $\begin{array}{l}\text { Respeita e participa dos projetos da escola, valorizando o } \\
\text { trabalho dos alunos e professores. }\end{array}$ & $\begin{array}{l}\text { Deixou a } \\
\text { desejar }\end{array}$ & Regular & Bom & Ótimo Excelente \\
\hline $\begin{array}{l}\text { Em caso de necessidade presta serviços de outra natureza } \\
\text { além da sua função. }\end{array}$ & $\begin{array}{l}\text { Deixou a } \\
\text { desejar }\end{array}$ & Regular & Bom & Ótimo Excelente \\
\hline Totais & & & & \\
\hline
\end{tabular}

Observações: 